ORIGINAL ARTICLE

\title{
Increased E2F-1 expression via tumour cell proliferation and decreased apoptosis are correlated with adverse prognosis in patients with squamous cell carcinoma of the oesophagus
}

\author{
K Yamazaki, M Hasegawa, I Ohoka, K Hanami, A Asoh, T Nagao, I Sugano, Y Ishida
}

J Clin Pathol 2005;58:904-910. doi: 10.1136/icp.2004.023127

\begin{abstract}
See end of article for authors' affiliations

Correspondence to: Dr K Yamazaki, Department of Pathology, Teikyo University, Ichihara Hospital, 3426-3 Anesaki, Ichihara City, Chiba, 2990111, Japan; yamas@ med.teikyo-u.ac.jp
\end{abstract}

Accepted for publication 4 February 2005
Background: The retinoblastoma (Rb) pathway, which governs cell cycle progression, is frequently genetically altered in cancer, causing deregulated expression of the E2F-1 transcription factor, which promotes DNA synthesis and cell cycle progression. Recent studies show that E2F-1 also participates in apoptosis induction in a p53 dependent or independent manner. Despite its crucial role and paradoxical effects on cell turnover, the function of E2F-1 in human cancer is unclear.

Aims: To evaluate E2F-1 expression using immunohistochemistry in 43 surgically resected oesophageal squamous cell carcinoma (OSCC) specimens.

Methods: This study analysed the association of E2F-1 with tumour cell proliferation and apoptosis and the upstream regulators modulating these processes, and its impact on patient outcome. Tumour cell proliferation and apoptosis were assessed as percentage of MIB-1 positive or apoptotic cells (MIB-1 labelling index (MI) and apoptotic index (AI)), respectively.

Results: Entire specimens showed abnormal expression of one or more upstream regulators of pRb/E2F-1. Although E2F-1 positivity was not associated with the expression of upstream regulators, it showed a linear and positive correlation with MI but not Al. Patients with high MI, low Al, or high E2F-1 positivity had significantly shorter recurrence free survival. By multivariate analysis, high $\mathrm{Ml}$ and low Al were independently associated with recurrence free survival, but E2F-1 was not.

Conclusions: Increased cell proliferation and decreased apoptosis are associated with adverse prognosis in patients with OSCC. Although E2F-1 remains a controversial prognostic factor, its expression was closely associated with tumour cell proliferation and might influence clinical outcome, mainly via cell cycle progression.
W ith the recent explosion of knowledge about the cell cycle, large numbers of genes that govern its regulation have been identified and characterised. Multiple components, such as cyclins, cyclin dependent kinases (CDKs), CDK inhibitors, retinoblastoma protein $(\mathrm{pRb})$, and $\mathrm{p} 53$ are implicated in the transition from one cell cycle phase to another. Furthermore, these proteins can physically interact with each other in a network in which the relative proportions of the antiapoptotic and proapoptotic molecules determine the sensitivity of tumour cells to cell death stimuli. For example, D-type cyclins bind and activate CDK4/CDK6, which phosphorylate pRb, and CDK inhibitors such as p16 and p21 can inhibit the function of CDKs in the cell cycle. In addition, p53 responds to different forms of cellular stress by targeting and activating genes, including the p2l gene, involved in growth arrest and cell death. ${ }^{1}$

"E2F-1 DNA binding sites have been identified in the promoter regions of many genes involved in DNA replication or cell cycle control, and drive cells from G1 into the S phase"

The transcription factor E2F-l is the best characterised member of the E2F family and has been identified as a key downstream target in the pRb pathway. ${ }^{1-3}$ E2F-1 DNA binding sites have been identified in the promoter regions of many genes involved in DNA replication (for example, dihydrofolate reductase, thymidine kinase, and DNA polymerase $\alpha$ ) or cell cycle control (for example, cyclin A, cyclin E, and CDK2), and drive cells from Gl into the
$S$ phase. ${ }^{4}$ E2F-1 has a transactivation domain in its Cterminal region, which is responsible for binding to $\mathrm{pRb}$, a member of the pocket protein family of tumour suppressors. ${ }^{5}{ }^{6}$ Hypophosphorylated pRb binds to E2F-1 and thereby downregulates its activity, suggesting a model in which $\mathrm{pRb}$ restricts cell cycle progression by restraining E2F-1. Evidence has shown that transcriptional activation by E2F-l is important in promoting cell proliferation, and that loss of $\mathrm{pRb}$ mediated control of E2F-1 activity leads to the progression of DNA synthesis. Furthermore, the fact that overexpression of E2F-1 results in malignant transformation of cultured cells and produces tumours in nude mice supports its putative role as an oncogene..$^{7-9}$

Despite its clear importance in allowing cell cycle progression, several studies have also suggested a role for E2F-1 in apoptosis. ${ }^{10-15}$ Moreover, the role of E2F-1 as a direct tumour suppressor is supported by the observation that E2F-1 deficient mice have impaired apoptotic function and an increased incidence of cancer. ${ }^{16}{ }^{17}$ Although several in vitro studies have demonstrated these paradoxical biological roles of E2F-1, only a few reports have discussed their impact on the prognosis of human tumours. Previous studies showed that E2F-1 overexpression is associated with worse prognosis in urothelial carcinoma of urinary bladder and squamous cell carcinoma of the tongue, ${ }^{18}{ }^{19}$ therefore suggesting that E2F- I acted as a tumour suppressor in these tumours.

Abbreviations: $\mathrm{Al}$, apoptotic index; $\mathrm{CDK}$, cyclin dependent kinase; HPV, human papillomavirus; LI, labelling index; MI, MIB-1 labelling index; OSCC, oesophageal squamous cell carcinoma; pRb retinoblastoma protein 
In contrast, some recent reports have shown a positive correlation between E2F-1 and proliferation indices, and that increased expression of E2F-1 is associated with an adverse prognosis in patients with cancers of the lung, breast, and pancreas. ${ }^{20-22}$ Furthermore, a recent study has shown that E2F-1 acts as a growth promoter in breast carcinoma and superficial transitional cell carcinomas of the urinary bladder, whereas it seems to act as a growth suppressor in colon and prostate cancer. ${ }^{11}$ These findings imply a tissue specific effect, so that the role of E2F-1 needs to be investigated in other tumours.

In view of the crucial and paradoxical role of E2F-1 in cell turnover, we wanted to determine whether E2F-1 expression is associated with cell proliferation or apoptosis-which have been identified as prognostic indicators-in oesophageal squamous cell carcinoma (OSCC). ${ }^{23-25}$ Therefore, we evaluated the E2F-l status in 43 surgically resected OSCC specimens from patients who had not been treated with chemotherapy or radiotherapy and analysed its association with tumour cell proliferation, apoptosis, and the molecules that regulate these two processes. In addition, we also analysed the clinical impact of E2F-l status on patient outcome.

\section{METHODS \\ Patients}

We studied 43 patients with OSCC who had been treated between 1986 and 1999. Our study was approved by the human subjects committee of Teikyo University Ichihara Hospital, Japan, and all the patients' information was dealt with anonymously. Table 1 shows the data on age, sex, stage, and grading. This cohort comprises 43 curative resection specimens that were obtained from our previous study. ${ }^{26}$ All the patients underwent transthoracic oesophagectomy, and none had received irradiation or chemotherapy before or after surgery. No distant metastases were present at the time of surgery. The tumours were classified histologically using the World Health Organisation criteria. We also classified the tumours using the TNM staging of oesophageal carcinoma. All of the surgical specimens were confirmed to have tumour free resection margins by pathological evaluation. The recurrence free survival time was from October 1986 to August 2002. At the end of the follow up period, 13 of the 43 patients were still alive. Median follow up after oesophageal resection for the nine patients censored was 1680 days (range, 414-4470). Median overall survival was 1027 days for the whole group.

\section{Immunohistochemical staining}

Immunohistochemistry was performed as described previously ${ }^{26}$; antigen retrieval was achieved by microwaving in

\begin{tabular}{|c|c|}
\hline $\begin{array}{l}\text { Clinicopathological } \\
\text { parameter }\end{array}$ & \\
\hline Age (years) & Range, 37.0-83.0; median, 60 \\
\hline Sex (female/male) & $6(14.0 \%) / 37(86.0 \%)$ \\
\hline $\begin{array}{l}\text { Tumour depth } \\
\text { (Tis/T1/T2/T3) }\end{array}$ & \\
\hline $\begin{array}{l}\text { Lymph node metastasis } \\
\text { (NO/N1) }\end{array}$ & $20(46.5 \%) / 23(53.5 \%)$ \\
\hline $\begin{array}{l}\text { Histological grade } \\
\text { (G1/G2/G3) }\end{array}$ & $12(27.9 \%) / 22(51.2 \%) / 14(32.6 \%)$ \\
\hline Stage $(0 / \mathrm{I} / \mathrm{Ila} / \mathrm{Ilb} / \mathrm{III})$ & $\begin{array}{l}2(4.7 \%) / 7(16.3 \%) / 11(25.6 \%) / 6 \\
(14.0 \%) / 17(39.5 \%)\end{array}$ \\
\hline $\begin{array}{l}\text { Additional treatment } \\
\text { (radiotherapy or radio/ } \\
\text { chemotherapy; yes/no) }\end{array}$ & $0 / 43(100 \%)$ \\
\hline
\end{tabular}

citrate buffer ( $\mathrm{pH} 7.0$ for cyclin D1 and E2F-1, pH 6.0 for others). Primary monoclonal antibodies were directed against p16 ${ }^{\text {INK4a }}$ (clone G175-405; 1/150 dilution; Pharmingen, Heidelberg, Germany), cyclin Dl (clone G124-326; 1/100 dilution; Santa-Cruz Biotechnology, Santa Cruz, California, USA), both phosphorylated and underphosphorylated $\mathrm{pRb}$ (clone G3-245; 1/500 dilution; Pharmingen), E2F-1 (clone KH95; 1/100 dilution; Santa-Cruz), and MIB-1 (1/100 dilution; Immunotech, Marseilles, France). We used lymphoid cells, fibroblasts, or non-neoplastic epithelial cells that showed positive nuclear staining as positive controls. For the negative controls, the primary antibodies were omitted. The p2l immunostaining data were taken from our previous study. ${ }^{26}$ Two observers without knowledge of the clinical data calculated the percentage of cells showing positive nuclear staining. Five representative fields were examined for each specimen, and more than 1000 tumour cells (200 for each field) were counted by microscopy with a high power $(\times 400)$ objective. The percentage of tumour cells positive for MIB-1 was recorded as the MIB-1 labelling index (MI, number of MIB-1 stained cells/100 tumour cells). We also counted the p16, pRb, p21, cyclin D1, and E2F-1 labelling indices (LIs) as the percentage of cells with positive nuclear staining for each antibody. All slides in the same batch were independently scored two or three times and all the batches were coded and scored blind at least twice. All immunostaining was interpreted in a similar manner by the two observers.

\section{Detection and interpretation of apoptosis}

The data on tumour cell apoptosis, detected by the terminal deoxynucleotidyl transferase mediated dUTP nick end labelling method, were taken from our previous study. ${ }^{26}$

\section{HPV DNA detection and mutation analysis of the p53 gene}

The data concerning the presence of human papillomavirus (HPV) DNA and the HPV subtypes seen, evaluated by the polymerase chain reaction, were taken from our previous study, ${ }^{26}$ as were the data on the mutational analysis of exons $5-8$ of the p53 gene. ${ }^{26}$

\section{Statistical analysis}

The data were analysed with the StatView 5.0 computer software package (SAS Institute Inc, Tokyo, Japan). For statistical analysis, clinicopathological variables were categorised as follows: Tl/T2 versus T3/T4, N0 versus N1, stages $\mathrm{I} / \mathrm{II}$ versus III/IV, grades Gl versus G2/G3, median ages $\geqslant 61$ versus $<61$ years, and female versus male. Immunohistochemical variables were categorised using a cutoff value for subsequent statistical analysis as follows: normal $\mathrm{pRb}(\mathrm{pRb} \mathrm{LI}, \geqslant 20$ ) versus decreased $\mathrm{pRb}$ (Rb LI, $<20$ ), normal cyclin Dl (cyclin D1 LI, $<10$ ) versus increased cyclin Dl (cyclin Dl LI, $\geqslant 10$ ), normal pl6 (pl6 LI, $\geqslant 70$ ) versus decreased p16 (p16 LI, < 70), normal p21 (p21 LI, $\geqslant 10$ ) versus decreased p2l (p21 LI, < 10) expression. Similar cutoff points for these proteins have been established independently by other groups. ${ }^{25} 2728$ We also categorised tumours by p53 status-normal versus abnormal (immunohistochemical overexpression or missense mutation or deletion). For intervariable assessment, the unpaired Mann-Whitney U test for continuous variables and Fisher's exact F test, where appropriate, were applied. Associations within continuous variables were examined with the nonparametric Spearman test. Survival analysis was carried out according to Kaplan-Meier methodology and Cox regression analysis. Differences at $\mathrm{p}<0.05$ were considered to be significant. 

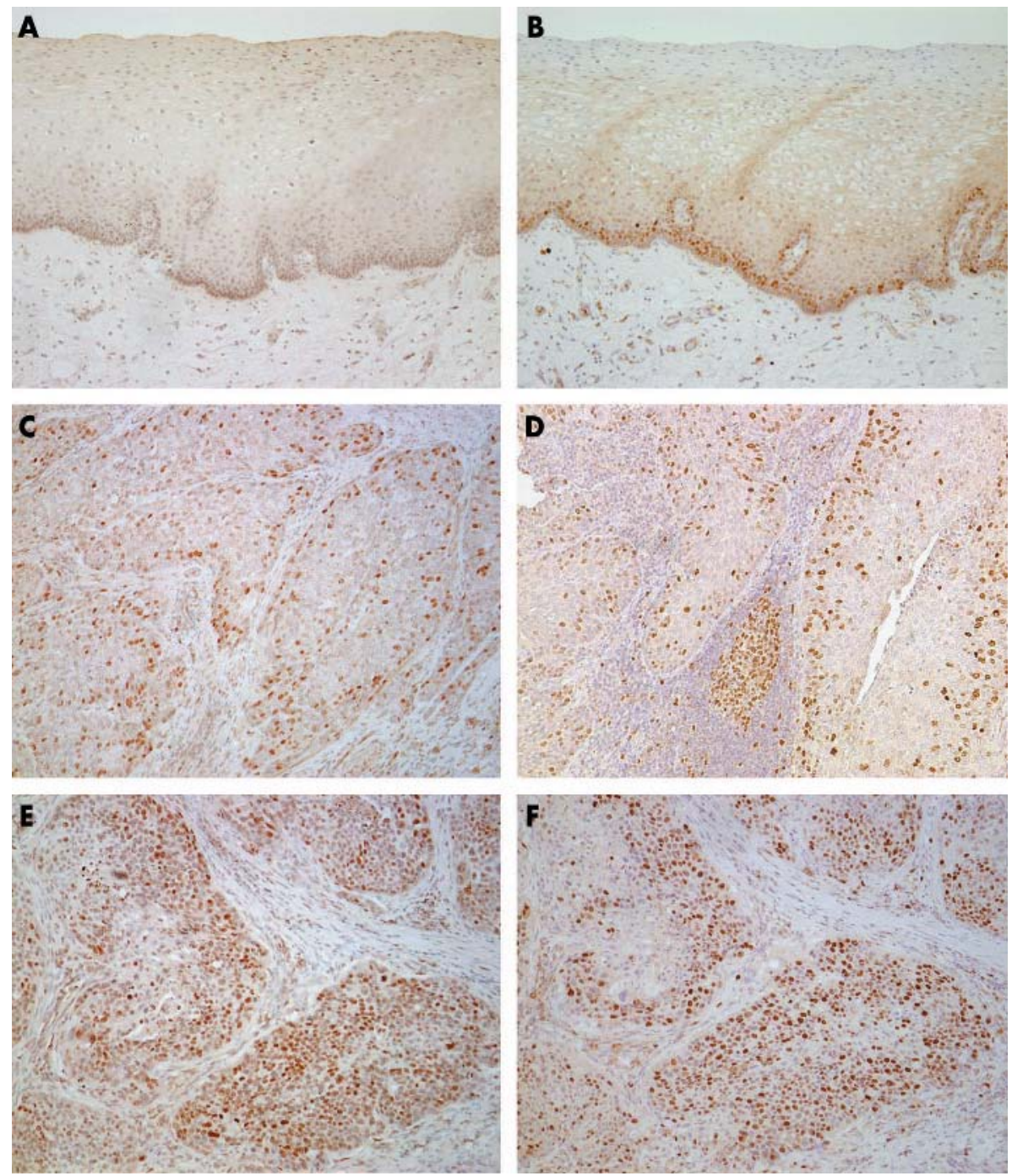

Figure 1 Representative results of E2F-1 and Ki-67 immunohistochemistry. In non-tumorous squamous epithelium, basal and parabasal cells showed (A) faint and sparse nuclear E2F-1 staining and (B) a low degree of Ki-67 positivity. Well differentiated squamous cell carcinoma showed a low degree of positivity for (C) E2F-1 and (D) Ki-67. Poorly differentiated squamous cell carcinoma showed a high degree of positivity for (E) E2F-1 and (F) Ki-67. Active stromal fibroblasts and infiltrating active lymphocytes in tumour and non-tumour specimens occasionally showed positive staining.

RESULTS

\section{E2F-1 status and its association with the} clinicopathological parameters

E2F-1 was expressed both in normal squamous epithelium and OSCC (fig 1). In normal squamous epithelium, E2F-1 staining was detected mainly in the basal and parabasal areas and its staining pattern was faint and sparse. In OSCC, E2F-l staining was confined mainly to the tumour cell nuclei throughout the entire specimen. Active stromal fibroblasts and infiltrating active lymphocytes in tumour and non-tumour specimens occasionally showed positive staining.

\begin{tabular}{|c|c|c|c|}
\hline Molecular parameters & Positivity (\%) & Altered & Normal \\
\hline Mean (SD; median) MI & $46.8(15.8 ; 47)$ & & \\
\hline Mean (SD; median) Al & $3.28(2.62 ; 3.2)$ & & \\
\hline Mean (SD; median) E2F-1 LI & $27.2(17.1 ; 25)$ & & \\
\hline pRB status & $47.8(31.4)$ & Decreased, 6 (14.0\%) & 37 (86.0\%) \\
\hline Cyclin DI status & $23.3(27.6)$ & Increased, 23 (53.5\%) & $20(46.5 \%)$ \\
\hline p16 status & $29.6(31.9)$ & Decreased, 33 (76.7\%) & $10(23.3 \%)$ \\
\hline p21 status & $22.3(21.8)$ & Decreased, 16 (37.2\%) & $27(62.8 \%)$ \\
\hline p53 status (overall) & & Abnormal, 24 (55.8\%) & $19(44.2 \%)$ \\
\hline Immunohistochemistry & & Increased, $14(32.6 \%)$ & $29(67.4 \%)$ \\
\hline Missense mutation/deletion & & $20(46.5 \%)$ & $23(53.5 \%)$ \\
\hline HPV infection status & & Positive, 18 (41.9\%) & Negative, 25 (58.1\%) \\
\hline
\end{tabular}



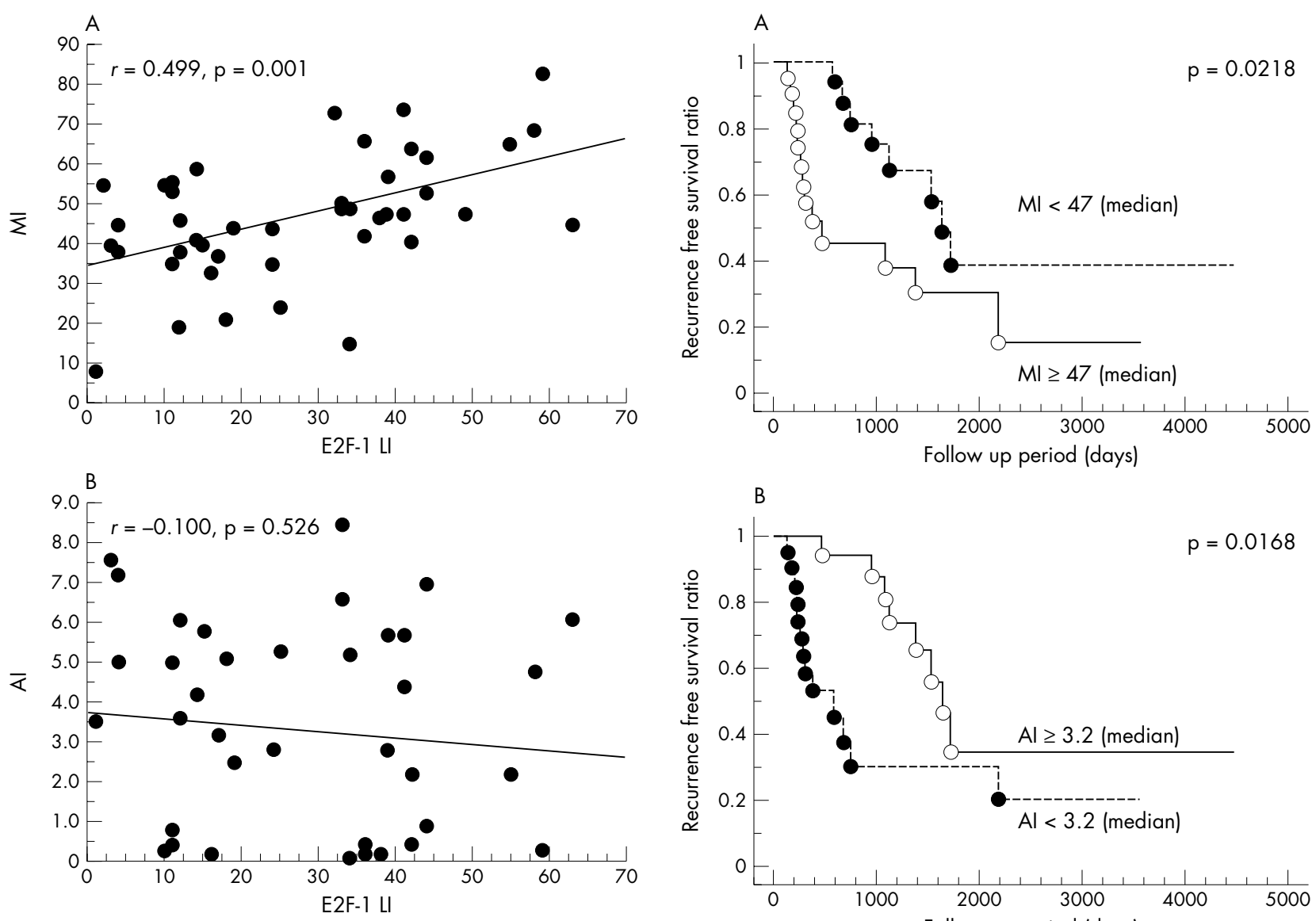

Figure 2 Scatter plots and linear regression fit lines showing the correlation between E2F-1 labelling index (LI) and (A) MIB-1 LI (MI) and (B) apoptotic index (AI). There was a significant positive correlation between E2F-1 LI and MI $(r=0.499, \mathrm{p}=0.001)$.

In the tumours, the mean E2F-1 LI was 27.2 (SD, 17.1; range, 1-63; table 2). There were no significant differences for E2F-1 status between the clinicopathological subgroups classified by histological grade, tumour depth, and lymph node involvement using the Mann-Whitney U test.

\section{Upstream regulators of tumour cell proliferation/ apoptosis and their association with clinicopathological parameters}

Table 2 summarises the immunohistochemical status of upstream regulators of the cell cycle and apoptosis. Using immunohistochemistry, six cases showed decreased or negative pRB expression, 23 showed increased cyclin Dl expression, 33 showed decreased pl6 expression, and 16 showed decreased p21 expression. In a previous analysis, ${ }^{26}$ we detected immunohistochemical p53 overexpression in 14 cases and missense mutations or deletions in exons 5-8 of the p53 gene in 20. Overall, 24 cases showed abnormal p53 status (immunohistochemical overexpression or deletion/ mutation). HPV infection was seen in 18 cases, which included 14 cases harbouring HPV-16 or HPV-18 infection. We found no significant correlation between these factors and the clinicopathological parameters using Fisher's exact F test.

The relation between E2F-1 and upstream regulators of tumour cell proliferation/apoptosis

We searched for an association between pRb, cyclin Dl, pl6, p21, p53, and HPV infection and E2F-1 LI by means of the Mann-Whitney U test, but no association was found.
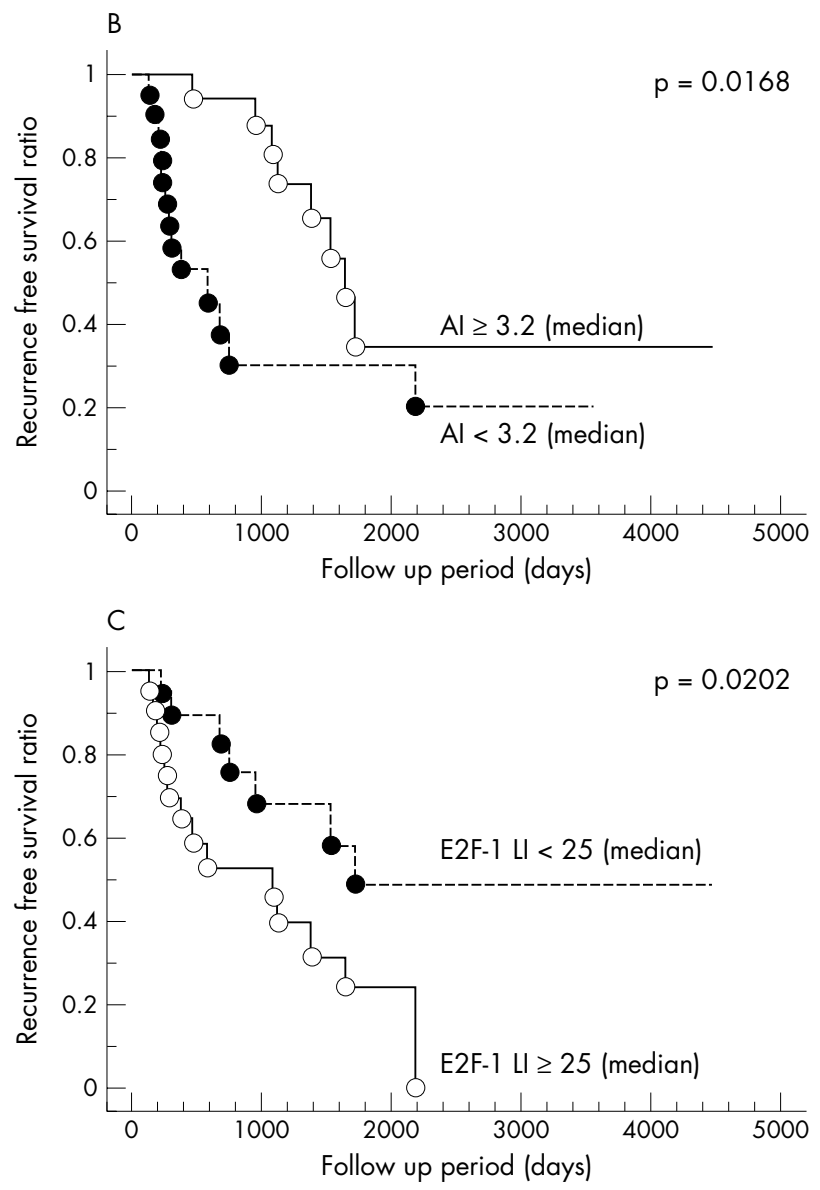

Figure 3 Kaplan-Meier postoperative survival curves of patients with oesophageal squamous cell carcinoma $(n=43)$. (A) The recurrence free survival rate of patients with high MIB-1 labelling index (MI) tumours was significantly lower than that of patients with low MI tumours $(p=0.0218)$. (B) The recurrence free survival rate of patients with low apoptotic index (Al) tumours was significantly lower than that of patients with high Al tumours $(p=0.0168)$. (C) There was also a significant association between high E2F-1 labelling index (LI) and worse clinical outcome $(p=0.0202)$.

\section{Tumour kinetic parameters (MI and AI) and their} relation to clinicopathological parameters

The median MI and AI values were 47\% (range, 8-83\%) and $3.2 \%$ (range, $1-8.5 \%$ ), respectively (table 2 ). MI and AI showed no significant differences between the clinicopathological subgroups classified by histological grade, tumour depth, or lymph node involvement by Fischer's extract F test. 
The relation between tumour kinetic parameters and regulators of tumour cell proliferation/apoptosis

Tumours with normal p2 l expression showed a significantly higher AI $(p=0.0083)$ than those with decreased $\mathrm{p} 21$ expression (Mann-Whitney $\mathrm{U}$ test), but this was not the case for MI $(p=0.679)$. We found no significant associations between $\mathrm{pRb}$, cyclin Dl, pl6, p53, or HPV infection and MI or AI.

\section{The relation between tumour kinetic parameters and E2F-1 expression}

Spearman's correlation efficiency test showed a strong positive correlation between E2F-1 LI and MI $(r=0.499$, $\mathrm{p}=0.001$; fig 2A). No association was found between E2F-1 $\mathrm{LI}$ and $\mathrm{AI}(r=-0.100, \mathrm{p}=0.526$; fig $2 \mathrm{~B})$.

\section{Survival analysis}

To determine the prognostic impact of each parameter, patients were stratified according to the dichotomised variables (table 3; fig 3). Univariate survival analysis showed that the median recurrence free survival of the 17 patients with $\mathrm{pTis} / \mathrm{Tl} / \mathrm{T} 2$ tumours was 1385 days, whereas that of the 26 patients with pT3 tumours was only 433 days $(\mathrm{p}=0.0026)$. The median recurrence free survival of the 20 patients who presented with stage No disease was 977 days, whereas that of the 23 patients with stage $\mathrm{Nl}$ was only 581 days $(\mathrm{p}=0.0007)$.

For survival analysis, we categorised tumours by MI (high MI (median, $\geqslant 47) v$ low MI $(<47)$ ), AI (high AI (median, ? 3.2) $v$ low $\mathrm{AI}(<3.2)$ ), and E2F-1 positivity (high E2F-1 LI (median, $\geqslant 25) v$ low E2F-1 LI $(<25)$ ). Interestingly, patients with high MI or low AI tumours showed poor overall recurrence free survival. The 21 patients with low MI tumours had a median recurrence free survival of 1102 days, whereas the 23 patients with high MI tumours had a median recurrence free survival of 291 days $(\mathrm{p}=0.0275$ by Cox regression and $\mathrm{p}=0.0218$ by Kaplan-Meier methodology; fig 3A). The median recurrence free survival of the 21 patients with high AI tumours was 1111 days, whereas that of the 22 patients with low AI tumours was only 365 days $(\mathrm{p}=0.0216$ by Cox regression and $\mathrm{p}=0.0168$ by KaplanMeier methodology; fig 3B). Finally, the median recurrence free survival of the 21 patients with low E2F-1 LI tumours was 956 days, whereas that of the 22 patients with high E2F-1 LI tumours was only 326 days. There was a significant association between high E2F-1 LI and poor patient outcome ( $\mathrm{p}=0.0420$ by Cox regression and $\mathrm{p}=0.0202$ by

Table 3 Univariate regression analysis, Cox proportional hazards model

\begin{tabular}{|c|c|c|c|}
\hline & RR & $95 \% \mathrm{Cl}$ & p Value \\
\hline Age ( $\geqslant 60$ years) & 0.731 & 0.296 to 1.744 & 0.4646 \\
\hline Sex (male) & 0.737 & 0.134 to 2.487 & 0.4611 \\
\hline pT (pT3 or 4$)$ & 3.191 & 0.038 to 0.672 & $0.0123^{*}$ \\
\hline $\begin{array}{l}\text { Lymph node metastasis } \\
\text { (positive) }\end{array}$ & 3.419 & 0.030 to 0.602 & $0.0087^{*}$ \\
\hline Grade (G2 or G3) & 0.539 & 0.248 to 2.210 & 0.5900 \\
\hline $\mathrm{MI}(\geqslant 47)$ & 2.205 & 0.152 to 0.895 & $0.0275^{*}$ \\
\hline $\mathrm{Al}(<3.2)$ & 2.297 & 0.142 to 0.857 & $0.0216^{*}$ \\
\hline E2F-1 LI ( $\geqslant 25)$ & 2.857 & 0.139 to 0.882 & $0.0259 *$ \\
\hline p21 니 $(<10)$ & 0.712 & 0.199 to 1.501 & 0.2413 \\
\hline p16 니 $(<70)$ & 0.352 & 0.608 to 3.440 & 0.7250 \\
\hline $\mathrm{pRb}$ LI $(<20)$ & 0.712 & 0.492 to 4.570 & 0.4765 \\
\hline Cyclin D1 $(\geqslant 10)$ & 0.079 & 0.409 to 2.282 & 0.9367 \\
\hline p53 mutation (positive) & 1.222 & 0.718 to 4.156 & 0.2218 \\
\hline HPV infection (positive) & 1.053 & 0.654 to 4.094 & 0.2924 \\
\hline
\end{tabular}

*Significant.

$\mathrm{Al}$, apoptotic index; $\mathrm{Cl}$, confidence interval; HPV, human papillomavirus; $\mathrm{LI}$, labelling index; MI, MIB-1 labelling index; RR, relative risk.
Kaplan-Meier methodology; fig 3C). However, Cox multivariate analysis showed that both MI and AI were independent prognostic factors $(\mathrm{p}=0.0039$ and $\mathrm{p}=0.0047$, respectively), but E2F-1 was not $(\mathrm{p}=0.2078)$ (table 4). In contrast to these parameters, pRb, pl6, p2l, cyclin Dl, and p53 status and HPV infection were not associated with patient outcome.

\section{DISCUSSION}

We found that E2F-l expression was higher in OSCC than in the corresponding adjacent non-tumorous squamous epithelium, and tumours with high E2F-1 positivity had significantly higher growth indices as assessed by immunohistochemistry. These results suggest that the underlying mechanisms involved in E2F-1 expression are upregulated in OSCC compared with non-tumorous squamous epithelium. Recent studies have shown that E2F-1 expression in some human tumours is increased at the transcriptional level without localised gene amplification. ${ }^{4829}$ Therefore, one possible explanation for our observation is that E2F-1 expression is increased in OSCC by a similar mechanism. In addition, previous in vitro experiments have shown that E2F-1 binding activity and the mRNA value fluctuate throughout the cell cycle, reaching a peak at the Gl-S phase boundary. ${ }^{7}$ Accordingly, it can be speculated that E2F-1 positive cells defined in OSCCs are mainly in the Gl-S phase as a result of upregulated progression of the cell cycle.

Although E2F-1 positivity was not associated with the expression of its upstream regulators, it showed a positive linear correlation with MIB-1 immunostaining and patients with increased E2F-l expression showed a worse clinical outcome. Recent studies of surgical specimens from various tumours have shown that tumour E2F-1 positivity positively correlates with MIB-1 immunopositivity. ${ }^{11}{ }^{20-22}$ These findings agree with our data, and support the hypothesis that E2F-1 expression is associated with tumour cell proliferation in OSCC.

As a result of pRb phosphorylation, activated E2F-1 initiates the transcription of genes that determine the progression of the cell cycle and others that activate apoptosis. The Rb gene is frequently mutated or deleted in many human cancers, and in tumours with an intact Rb gene there is usually some other abnormality of the upstream regulators in this pathway. For example, overexpression of cyclin Dl and mutation/deletion or methylation of the pl6 CDKI gene, resulting in its functional deficiency, are common events in OSCC. ${ }^{28}$ To examine whether such deregulated upstream regulators result in increased E2F-1 expression, we attempted to examine the combined results by classifying the patients into those with a normal and those with an altered pl6/cyclin Dl/pRb status. However, 42 of the 43 cases harboured one or more disruption in this pathway, including decreased pl6 expression (33 of 43), increased cyclin Dl expression (23 of 43), and decreased/negative pRb expression ( six of 43). In addition, the only patient with a normal pl6/

Table 4 Multivariate regression analysis, Cox proportional hazards model

\begin{tabular}{llll}
\hline & RR & $\mathbf{9 5 \%}$ Cl & p Value \\
\hline pT (pT3 or 4) & 6.215 & 0.000 to 0.053 & $0.0002^{*}$ \\
Lymph node metastasis & 2.833 & 0.009 to 0.398 & $0.0037^{*}$ \\
(positive) & & & \\
MI $(\geqslant 47)$ & 3.255 & 0.005 to 0.307 & $0.0039^{*}$ \\
Al $(<3.2)$ & 2.504 & 0.014 to 0.464 & $0.0047^{*}$ \\
E2F-1 LI $(\geqslant 25)$ & 0.747 & 0.148 to 1.515 & 0.2078 \\
\hline
\end{tabular}

*Significant.

Al, apoptotic index; $\mathrm{Cl}$, confidence interval; Ll, labelling index; $\mathrm{Ml}$, mitotic index; $R R$, relative risk. 
cyclin D1/pRb status was infected with HPV-16. Although we could not demonstrate the association between the E2F-1 expression and these factors, the entire tumour specimens harboured deregulated upstream signals of the $\mathrm{pRb} / \mathrm{E} 2 \mathrm{~F}-\mathrm{l}$ pathway, which probably resulted in the release of E2F-1 from $\mathrm{pRb}$ mediated repression, thus promoting tumour cell cycle progression.

"Increased E2F-1 expression appeared to be associated with cell cycle progression, but had no apparent influence on tumour cell apoptosis in our study"

Some previous in vitro studies have shown that E2F-1 overexpression directly activates the expression of $\mathrm{pl} 4^{\mathrm{ARF}}$, which inhibits MDM2 mediated p53 degradation. A recent study showed that the sequential transfer of the wild-type p53 and E2F-1 genes into oesophageal cancer cells induces tumour cell apoptosis via this E2F-1/ARF/MDM/p53 pathway. ${ }^{27}$ However, increased E2F-1 expression appeared to be associated with cell cycle progression, but had no apparent influence on tumour cell apoptosis in our study. Interestingly, a recent study of E2F-1 in non-small cell lung carcinoma yielded similar results. ${ }^{21}$ The authors suggested a model whereby tumours with a deregulated E2F-1/pRb network cannot promote $\mathrm{p} 53$ dependent apoptosis under conditions of p53 mutation or MDM2 overexpression. Although we did not investigate MDM2 expression in detail, 24 cases showed abnormal p53 status and six had decreased/negative pRb expression. Overall, 28 cases were considered to have abnormal p53 or pRb status, so that E2F-1-mediated apoptosis was probably defective in these cases. In addition, we found that 18 patients had high risk HPV infection, which is similar to the infection rate seen in Asian countries. ${ }^{30}$ The mechanisms by which the HPV viral oncoproteins E6 and E7 overcome normal cell cycle control involve inactivation of two major tumour suppressor proteins: 553 and pRb. ${ }^{31}$ E7 inhibits the pRb pathway, which may contribute to the release of E2F-1 from pRb mediated repression, thus promoting tumour cell proliferation. In addition, because E6 inhibits the function of $\mathrm{p} 53$ by directing its ubiquitination and degradation, p53 induced apoptosis may have been defective in a considerable proportion of our cases. Furthermore, a recent study showed that the CDKN2A (p16 ${ }^{\text {INK4A }}$ and p14 $\left.{ }^{\mathrm{ARF}}\right)$ gene was affected through mutations, deletions, and promoter hypermethylation in more than $80 \%$ of OSCC cases. ${ }^{32}$ It is possible that such genetic alterations affected E2F-1 mediated apoptosis in a considerable proportion of our patients. Recently, an in vitro study by Yang et al reported that E2F-1 mediated apoptosis in oesophageal cancer cell lines is not dependent on p53 expression, but is related to the differential expression of Bcl-2 family member proteins. ${ }^{33}$ Thus, further studies of E2F-1 mediated apoptosis in OSCC should investigate not only its association with p53, but also with these apoptosis related factors.

The E2F-1 LI was not significantly related to lymph node metastasis or a worse clinical stage. Clinical staging categorises the degree of cancer advancement, based on features of tumour spread, invasion, and metastasis. Although it has been reported that E2F-1 can regulate cell proliferation, there is no evidence of direct regulation of gene transcription of proteins that promote tumour invasiveness or metastasis. Our data are thus consistent with the known functions of E2F-1-integration of upstream signals from a variety of cell cycle regulators and promotion of cell cycle progression.

In conclusion, cell proliferation and apoptosis appear to be significantly associated with clinical outcome in patients with OSCC who have not undergone chemotherapy or
Take home messages

- Cell proliferation and apoptosis are associated with clinical outcome in patients with oesophageal squamous cell carcinoma (OSCC)

- E2F-1 expression in OSCC is positively associated with tumour cell proliferation but not with apoptosis

- Patients with increased E2F-1 expression had significantly shorter recurrence free survival, so that E2F-1 might have influenced clinical outcome mainly by its effects on cell cycle progression

radiotherapy. E2F-1 expression is positively associated with tumour cell proliferation and not with apoptosis. Our results were consistent with previous studies demonstrating that E2F-1 upregulates the cell cycle and promotes cell cycle progression directly or indirectly. In addition, patients with increased E2F-1 expression had a significantly shorter recurrence free survival time. Thus, in our series, E2F-1 might have influenced the clinical outcome mainly via cell cycle progression.

\section{Authors' affiliations}

K Yamazaki, M Hasegawa, I Ohoka, A Asoh, I Sugano, Y Ishida, Department of Pathology, Teikyo University, Ichihara Hospital, Ichihara, 3426-3 Anesaki, Ichihara City, Chiba, 299-0111, Japan

K Hanami, Department of Pathology, Saitama Medical Centre, Saitama Medical School, Saitama, 350-8550 Japan

T Nagao, Department of Surgical Pathology, Tokyo Medical University, Shinjuku, Tokyo, 160-0023 Japan

\section{REFERENCES}

1 Sherr CJ. Cancer cell cycles. Science 1996;274:1672-77.

2 Hiebert SW, Chellappan SP, Horowitz JM, et al. The interaction of RB with E2F coincides with an inhibition of the transcriptional activity of E2F. Genes Dev 1992:6:177-85.

3 Helin K, Wu CL, Fattaey AR, et al. Heterodimerization of the transcription factors E2F-1 and DP-1 leads to cooperative trans-activation. Genes Dev 1993;7:1850-61.

4 Helin K. Regulation of cell proliferation by the E2F transcription factors. Curr Opin Genet Dev 1998;8:28-35.

5 Dyson N. The regulation of E2F by pRB-family proteins. Genes Dev 1998; 12:2245-62.

6 Ginsberg D, Vairo G, Chittenden T, et al. E2F-4, a new member of the E2F transcription factor family, interacts with p107. Genes Dev 1994;8:2665-79.

7 Johnson DG, Schwarz JK, Cress WD, et al. Expression of transcription factor E2F1 induces quiescent cells to enter $S$ phase. Nature 1993;365:349-52.

8 Johnson DG, Cress WD, Jakoi L, et al. Oncogenic capacity of the E2F1 gene. Proc Natl Acad Sci U S A 1994;91:12823-7.

9 Pierce AM, Gimenez-Conti IB, Schneider-Broussard R, et al. Increased E2F1 activity induces skin tumors in mice heterozygous and nullizygous for p53. Proc Natl Acad Sci U S A 1998;95:8858-63.

10 Field SJ, Tsai FY, Kuo F, et al. E2F-1 functions in mice to promote apoptosis and suppress proliferation. Cell 1996;85:549-61.

11 Zacharatos P, Kotsinas A, Evangelou K, et al. Distinct expression patterns of the transcription factor E2F-1 in relation to tumour growth parameters in common human carcinomas. J Pathol 2004;203:744-53.

12 DeGregori J, Leone G, Miron A, et al. Distinct roles for E2F proteins in cell growth control and apoptosis. Proc Natl Acad Sci U S A 1997;94:7245-50.

13 Tsai KY, Hu Y, Macleod KF, et al. Mutation of E2f-1 suppresses apoptosis and inappropriate $\mathrm{S}$ phase entry and extends survival of $\mathrm{Rb}$-deficient mouse embryos. Mol Cell 1998;2:293-304.

14 Pierce AM, Schneider-Broussard R, Gimenez-Conti IB, et al. E2F1 has both oncogenic and tumor-suppressive properties in a transgenic model. Mol Cell Biol 1999; 19:6408-14.

15 Nicholson SA, Okby NT, Khan MA, et al. Alterations of pl4ARF, p53, and p73 genes involved in the E2F-1-mediated apoptotic pathways in non-small cell lung carcinoma. Cancer Res 2001:61:5636-43.

16 Yamasaki L, Jacks T, Bronson R, et al. Tumor induction and tissue atrophy in mice lacking E2F-1. Cell 1996;85:537-48.

17 Yamasaki L, Bronson R, Williams BO, et al. Loss of E2F-1 reduces tumorigenesis and extends the lifespan of $\mathrm{Rbl}(+/-)$ mice. Nat Genet 1998; 18:360-4.

18 Rabbani F, Richon VM, Orlow I, et al. Prognostic significance of transcription factor E2F-1 in bladder cancer: genotypic and phenotypic characterization. J Natl Cancer Inst 1999;91:874-81. 
19 Kwong RA, Nguyen TV, Bova RJ, et al. Overexpression of E2F-1 is associated with increased disease-free survival in squamous cell carcinoma of the anterior tongue. Clin Cancer Res 2003;9:3705-11.

20 Zhang SY, Liu SC, Al-Saleem LF, et al. E2F-1: a proliferative marker of breast neoplasia. Cancer Epidemiol Biomarkers Prev 2000;9:395-401.

21 Gorgoulis VG, Zacharatos P, Mariatos G, et al. Transcription factor E2F-1 acts as a growth-promoting factor and is associated with adverse prognosis in non-small cell lung carcinomas. J Pathol 2002;198:142-56.

22 Yamazaki K, Yajima T, Nagao T, et al. Expression of transcription factor E2F1 in pancreatic ductal carcinoma: an immunohistochemical study. Pathol Res Pract 2003;199:23-8.

23 Ikeda G, Isaji S, Chandra B, et al. Prognostic significance of biologic factors in squamous cell carcinoma of the esophagus. Cancer 1999;86:1396-405.

24 Matsumoto M, Natsugoe S, Nakashima S, et al. Clinical significance and prognostic value of apoptosis related proteins in superficial esophageal squamous cell carcinoma. Ann Surg Oncol 2001;8:598-604.

25 Shibata H, Matsubara O. Apoptosis as an independent prognostic indicator in squamous cell carcinoma of the esophagus. Pathol Int 2001:51:498-503.

26 Hasegawa M, Ohoka I, Yamazaki K, et al. Expression of p21/WAF-1, status of apoptosis and p53 mutation in esophageal squamous cell carcinoma with HPV infection. Pathol Int 2002;52:442-50.
27 Natsugoe S, Nakashima S, Matsumoto $M$, et al. Expression of p21WAF1/Cipl in the p53-dependent pathway is related to prognosis in patients with advanced esophageal carcinoma. Clin Cancer Res 1999:5:2445-9.

28 Guner D, Sturm I, Hemmati $\mathrm{P}$, et al. Multigene analysis of Rb pathway and apoptosis control in esophageal squamous cell carcinoma identifies patients with good prognosis. Int J Cancer 2003;103:445-54.

29 Suzuki T, Yasui W, Yokozaki H, et al. Expression of the E2F family in human gastrointestinal carcinomas. Int J Cancer 1999:81:535-8.

30 Syrianen KJ. HPV infections and oesophageal cancer. J Clin Pathol 2002;55:721-8.

31 Zhou XB, Guo M, Quan LP, et al. Detection of human papillomavirus in Chinese esophageal squamous cell carcinoma and its adjacent normal epithelium. World J Gastroenterol 2003:9:1170-3.

32 Smeds J, Berggren P, MaX, et al. Genetic status of cell cycle regulators in squamous cell carcinoma of the oesophagus: the CDKN2A (pl6(INK4a) and pl $4(A R F)$ and p53 genes are major targets for inactivation. Carcinogenesis 2002;23:645-55.

33 Yang HL, Dong TB, Elliott ML, et al. Caspase activation and changes in Bcl-s family member protein expression associated with $\mathrm{E} 2 \mathrm{~F}-1$ mediated apoptosis in human esophageal cancer. Clin Cancer Res 2000;6:1579-89.

\section{bmjupdates+}

bmjupdates+ is a unique and free alerting service, designed to keep you up to date with the medical literature that is truly important to your practice.

bmjupdates+ will alert you to important new research and will provide you with the best new evidence concerning important advances in health care, tailored to your medical interests and time demands.

\section{Where does the information come from?}

bmiupdates+ applies an expert critical appraisal filter to over 100 top medical journals A panel of over 2000 physicians find the few 'must read' studies for each area of clinical interest

Sign up to receive your tailored email alerts, searching access and more...

www.bmjupdates.com 